\title{
Analysis of blood transfusion request and utilization pattern at teaching hospital in Eastern Nepal
}

\author{
Santosh Upadhyaya Kafle ${ }^{1}$, Krishna Kumar Jha ${ }^{1}$, Mrinalini Singh ${ }^{1}$, Shilpi \\ Shaukin ${ }^{1}$ \\ ${ }^{I}$ Department of Pathology, Birat Medical College and Teaching Hospital, Tankisiniwari, Morang, Nepal
}

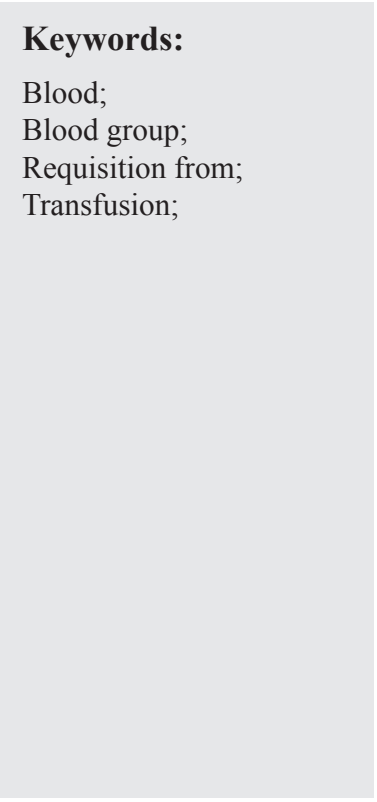

\begin{abstract}
Background: Blood transfusion unit collection, storage and dispatching on Birat Medical College and Teaching Hospital began from 19 June 2016 via blood bank. After which, many blood distribution were made accessible via this service. This study analyzes the blood transfusion request and utilization pattern and also to monitor for managing the bloodstocks meeting present and future demand in hospital.
\end{abstract}

Materials and Methods: This is descriptive cross-sectional study conducted for all the requests of whole blood dispatched from 19th June, 2016 to 04th July, 2018. Whole blood requisitions from various departments were reviewed regarding the number of requisition, total blood unit replaced, blood group and socio-demographic profile of patients.

Results: Of 648 transfusion units dispatched, 131 and 324 patients were male and female respectively, B positive blood group were most common, followed by A positive, $\mathrm{O}$ positive, $\mathrm{AB}$ positive, A negative, $\mathrm{O}$ negative and $\mathrm{AB}$ negative respectively. The largest numbers of requisitions were from Gynecology and Obstetric department in the hospital of 258 requisitions followed by internal medicine, surgery department, postoperative ward and orthopaedic department. Majority of the requisitions were for 20-29 years age group from the local district Morang. The total blood units replaced were 75, of which 29 and 46 of male and female respectively.

Conclusions: B Positive was the predominant requested blood group with Gynecology and Obstetrics department making the most requests, among 20-29 years age group from Morang district. The total replaced blood units were less in number with some requisition forms even lacked essential details.

\section{Correspondence:}

Dr. Santosh Upadhyaya Kafle, $M D$

Associate Professor, Department of Pathology,

Birat Medical College and Teaching Hospital, Tankisiniwari, Morang,

Nepal

ORCID ID: 0000-0002-7743-0485

Email:drsantoshkafle@gmail.com

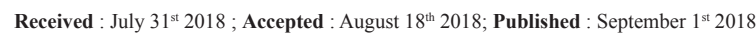

Citation: Kafle SU, Jha KK, Singh M, Shaukin S. Analysis of blood transfusion request and utilization pattern at teaching hospital in Eastern Nepal. J Pathol Nep 2018;8:1374-7. DOI: 10.3126/ jpn.v\%vi\%i.20889

Copyright: This is an open-access article distributed under the terms of the Creative Commons Attribution 4.0 International License, which permits unrestricted use, distribution, and reproduction in any medium, provided the original author and source are credited.

\section{INTRODUCTION}

Blood transfusion plays vital roles in the practice of medical and surgical field ${ }^{1}$ It has become an integral part of patient management in modern medicine, being vital and lifesaving procedures when given appropriately. In order to achieve these, the blood transfusion has to be appropriate and judicious. Availability of adequate safe blood has been challenging in developing countries due to reduced voluntary blood donors, poor facilities for storage and blood component preparation as well as inappropriate blood ordering and utilization. ${ }^{2-4}$ Like drugs, the blood and its component have property causing the adverse reactions in 


\begin{tabular}{lc} 
Table 1: ABO and Rh Blood group distribution \\
\hline \multicolumn{1}{c}{ Blood Group } & N (\%) \\
\hline B "Positive" & $217(33.48 \%)$ \\
\hline A "Positive" & $188(29.01 \%)$ \\
\hline 0 "Positive" & $179(28.72 \%)$ \\
\hline AB "Positive" & $56(08.64 \%)$ \\
\hline A "Negative" & $03(0.46 \%)$ \\
\hline O "Negative" & $03(0.46 \%)$ \\
\hline AB "Negative" & $02(0.30 \%)$ \\
\hline TOTAL & $\mathbf{6 4 8}(\mathbf{1 0 0} \%)$ \\
\hline
\end{tabular}

the recipients, though they are important part of the patient management treatment protocols. ${ }^{5}$ Blood bank service facility of blood collection, storage and dispatching began from 19 June 2016 in the new blood bank and transfusion service unit, at Kathmandu University Birat Medical College and Teaching Hospital, Tankisinuwari, Morang, Nepal. It is established under the supervision of Nepal Red Cross Society of Eastern Region, Nepal. However, the patterns of blood transfusion and its utilization have changed considerably in blood banking techniques, increase number of complicated surgical procedures, aging populations and a decrease in donors availability due to strict screening criteria. $^{6,7}$

Therefore, the treating physicians should be alert regarding the appropriate indication for ordering blood and its components, avoiding the unnecessary exposure and misuse of the recipient to various infectious and other non-infectious complications. For which, the regular audit of blood and its components usage is mandatory for accessing the blood utilization pattern and setting up the ideal policies in all the blood using specialties. Among such, the clinical audit is a management tools for the appraisal and justification of appropriateness and efficacy of transfusion therapy. ${ }^{8}$ Not only this, but could be a key factor of the quality assurance program providing the necessary information for improving the transfusion medicine practice. ${ }^{9}$ With the supply of blood being finite and with the added recognition of a high rate of inappropriate use of blood and its component services around the world, there is a need to monitor and regulate these services. Such studies related to the surveys on blood requisition and its usage pattern from low developing country like ours is rare.

Hence, this study was designed to analyze the blood transfusion request and utilization pattern in our newly established hospital. Also to monitor for managing the blood stocks to meet the present and future demand in hospital.

\section{MATERIALS AND METHODS}

This is a descriptive cross-sectional study conducted at Birat Medical College and Teaching Hospital (BMCTH), Tankisiniwari, Morang, Nepal for all the requests of whole blood dispatched from $19^{\text {th }}$ June, 2016 to $04^{\text {th }}$ July,
Table 2: Requests for blood transfusion from various departments

\begin{tabular}{lc}
\hline \multicolumn{1}{c}{ Blood Group } & N (\%) \\
\hline Gynecology \& Obstetrics & $258(39.8 \%)$ \\
\hline Internal Medicine & $174(26.8 \%)$ \\
\hline Surgery & $116(17.9 \%)$ \\
Postoperative ward & $28(4.3 \%)$ \\
Orthopedic & $15(2.3 \%)$ \\
ENT & $02(0.3 \%)$ \\
\hline Other health centers & $55(8.4 \%)$ \\
\hline TOTAL & $\mathbf{6 4 8}(\mathbf{1 0 0} \%)$ \\
\hline
\end{tabular}

2018. Permission was obtained from ethical committee. Some patients even had multiple admissions and multiple transfusions for different indications. For which, all the required transactions and data from $19^{\text {th }}$ June 2016 to $04^{\text {th }}$ July 2018 were noted from the main registration record of the Blood Bank Service Unit of Nepal Red Cross Society (NRCS) at Kathmandu University Birat Medical College and Teaching Hospital, Tankisiniwari, Morang, Nepal. Among them, the requisitions for whole blood requirement for patients from various departments were reviewed regarding the department requesting it, the number of whole blood requested and whether being replaced back, blood group and socio-demographic profile (age and gender) as well for the above dates. Simple descriptive statistical analysis was done wherever required.

\section{RESULTS}

The present study was conducted for 648 transfusion units dispatched for different blood groups over a period from 19 June 2016 to 04 July 2018. Out of total 648 transfusion units, $159(24.53 \%)$ patients were male and 489 (75.47\%) were females. Of the blood group among dispatched units, B positive were most common of 217 (38.35\%) followed by A positive of 188 (29.01\%), O positive of 179 (27.63\%), AB positive of $56(8.64 \%)$, A negative of $3(0.46 \%)$, O negative of $3(0.46 \%)$ and $\mathrm{AB}$ negative of $2(0.30 \%)$ respectively (Table 1). The largest numbers of requisitions for 258 transfusion units were from Gynecology and Obstetrics ward, followed by Internal Medicine, General Surgery, Postoperative ward, Orthopaedic ward and ENT ward for 174, 116, 28, 15 and 2 transfusion units respectively (Table 2). 55 requisites were from other hospital outside the Birat Medical College and Teaching Hospital. Majority of the requisitions were of 51- 60 years age group for male and 20-29 years age group for female (Table 3) from the local district Morang followed by neighboring district Sunsari. The total blood units replaced were 38 , out of which 5 of male and 33 of female.

\section{DISCUSSION}

This study describes the blood utilization pattern along with the different blood group demand for preparing its future 
Table 3: Age-wise distribution of patients requiring blood transfusion

\begin{tabular}{lccccccc}
\hline \multicolumn{1}{c}{ Average age of patients (year) } & $\mathbf{0 - 9}$ & $\mathbf{1 0 - 1 9}$ & $\mathbf{2 0 - 2 9}$ & $\mathbf{3 0 - 3 9}$ & $\mathbf{4 0 - 4 9}$ & $>\mathbf{5 0}$ & Total \\
\hline Total number of Male & 05 & 15 & 23 & 29 & 15 & 72 & 159 \\
Total number of Female & 03 & 50 & 218 & 104 & 55 & 59 & 489
\end{tabular}

requirements of the Birat Medical College, Tankisiniwari, Nepal and other nearby surrounding health centers. A study conclusion narrated by Venkatachalapathy and Das ${ }^{4}$ states the importance of periodic review of the blood and its component usage pattern in hospital. According to the study, the judicious implementation of guidelines for use of various blood components may help decrease in the inappropriate use of blood and its components. Not only this, but instead will ensure the availability of the blood and its component to needy patients and save many patients from the transfusion related reactions as well. Likewise, our study here as well demonstrates the very initial status and figures of the newly established blood storage, collection and dispatching centers. In addition, being within the tertiary care medical college and teaching hospital with the existing almost all departments of medical education, the future demand and use of such blood and its components would be in high number. The result of our study yielding more numbers of female than male patients from Morang district followed by Sunsari district demanding the whole blood definitely links the high volume of Gynecology and Obstetrics patients followed by the General surgery and other ward respectively in our and nearby geographical areas. Among them, the maximum age group of the patients falling within the fifth and sixth decade of life. Likewise, the recorded data showed of the 55 requisites of blood units were from the patients belongings other health centers besides Birat Medical College and Teaching Hospital, Tankisiniwari, Morang, Nepal. This ultimately becomes a useful tool in making the different blood transfusion related strategy and policies for future preparedness and action. In another way, we can even predict from the result about the vulnerable age group, geographical areas and the type of diseases having the exact indication of blood transfusion.

Similarly, our study concluded of total 648 blood units being dispatched with the majority of blood group being $\mathrm{B}$ positive followed by $\mathrm{A}$ positive, $\mathrm{O}$ positive, $\mathrm{AB}$ positive, A negative, $\mathrm{O}$ negative and $\mathrm{AB}$ negative respectively. This sort of internal audit data not only helps in tracing out the exact use and prepare for future demand of the individual blood units, but can play a vital function for quality control mechanism even. These facts in detail have been prescribed and proved in the studies done by McCullough $\mathrm{J}$ and Steeper TA et al and Silver $\mathrm{H}$ and Tahhan HR et al ${ }^{10,11}$ where the internal audits form an integral part of the quality control programme in any blood bank, like in any other organization. Studies done by Brandia K et al and Joshi GP et al $^{12,13}$ has the common conclusion, stating about the easy and indiscriminate use of blood components is on a high demand for its easy availability of sophisticated blood banking services. Thus, the blood bank should be able to update and fulfill the demand for this life saving product. Moreover, should be able to evaluate and access the existing systems and trends of ordering the blood units.

Considering these facts of the blood and its component being one of the lifesaving products, the blood bank should always try to maintain the replacing blood units after delivering or dispatching of each blood units. So, the blood units storing in the blood bank are always maintained for each and every demand of it. Unlike this fact, our study showed the result of minimal number of replaced blood units after dispatching of each blood units. Out of 648 total dispatched blood units, only 38 blood units by 33 female and 5 male replaced the dispatched blood units. Such number for tendency of replacing the dispatched blood units in the blood bank should be increased, so that every demand and requisites for blood units would be fulfilled to overcome any life threatening situations demanding the use of blood and its components. Likewise our study showed that, some of the requisition forms demanding such blood units even lacked the necessary and important details within. This was one of the unwanted findings we came across in our study. In another way, we can interpret that the necessary details about the patients identification considering the full name, age, sex, proper address, blood group (if already known), total blood units required, clinical or working diagnosis if possible etc. should be clearly mentioned in every such blood units requisition form.

Finally, we would achieve more favorable result if up gradation of blood storage and other facilities at the blood bank to deal with more inventories would be done. Similarly, a software based system for monitoring stock and predicting utilization is mandatory. Generating a list of donors to be used in cases of shortage, to avoid examples of non-availability would be a great step for regular supply of such blood units. In addition, continual education programs to improve the performance of any related staffs would prove for a fruitful exercise to increase the appropriate use of whole blood and its component.

\section{CONSLUSION}

B positive blood unit followed by A positive was the predominant requested blood units. The Gynecology and Obstetrics Department followed by the Internal Medicine Department at the institute making the most requests. The total replaced blood units were very less in number. Some requisition forms even lacked the essential details. Finally, these results could be useful for estimating/planning the 
requirements for our newly established Blood Bank to meet the demand in future. However, this study highlighted the importance of understanding the epidemiology of blood transfusion with its utilization pattern locally to monitor for managing the blood stocks to meet present and future demand in hospital.

\section{LIMITATIONS OF STUDY}

Our study was concluded with the only data available from the registration book maintained at the blood bank service at Birat Medical College and Teaching Hospital, Tankisiniwari, Morang, Nepal, which represents only a small proportion in Eastern Nepal.

\section{ACKNOWLEDGMENT}

Authors would like to acknowledge all the blood bank unit staff and Mr. Sanjit of Clinical Laboratory Service unit of Birat Medical College and Teaching Hospital, Tankisiniwari, Morang, Nepal.

\section{Conflict of interest: None}

\section{REFERENCES}

1. Dutta $A B$. Transfusion practice clinical aspects and applications. In: Blood Banking and Transfusion 1st ed. New Delhi: CBS Publishers; 2006. p.213-321.

2. Kagu MB, Ahmed SG, Askira BH. Utilization of Blood Transfusion Services in North Eastern Nigeria. Highland Med R J 2007;5:2730.
3. Kuliya-Gwarzo A. survey of blood transfusion needs in a tertiary Nigerian institute. Sahel Med J 2007;10:19-23. Crossref

4. Enosolease ME, Imarengiaye C, Awodu AO. Donor blood procurement and utilization at the University of Benin Teaching Hospital, Benin City. Afr J Reprod Health 2004;8:59-63. Crossref

5. Vishwanathan C, Jain R, Kamath M (1999) Blood utilization review in a tertiary care hospital. Indian J Haematol Blood Transf 17: 2631 .

6. Zimmermann R, Büscher M, Linhardt C, et al. A survey of blood component use in a German university hospital. Transfusion. 1997;37:1075-83. Crossref

7. Ali A, Auvinen MK, Rautonen J. The aging population poses a global challenge for blood services. Transfusion. 2010;50:584-8. Crossref

8. Luk C, Eckert KM, Barr RM, Chin-Yee IH. Prospective audit of the use of fresh-frozen plasma, based on Canadian Medical Association transfusion guidelines. CMAJ 2002;166:1539-40. $\underline{\text { Crossref }}$

9. Metz J, McGrath KM, Copperchini ML, et al. Appropriateness of transfusions of red cells, platelets and fresh frozen plasma. An audit in a tertiary care teaching hospital. Med J Aust 1995;162:572-3. $\underline{\text { Crossref }}$

10. McCullough J, Steeper TA, Connelly DP, et al. Platelet utilization in a university hospital. JAMA 1988;259:2414-8. Crossref

11. Silver H, Tahhan HR, Anderson J, Lachman M. A non-computerdependent prospective review of blood and blood component utilization. Transfusion 1992;32: 260-5. Crossref

12. Brandis K, Richards B, Ghent A, Weinstein S. A strategy to reduce inappropriate red blood cell transfusion. Med J Aust 1994;160:721-2. Crossref

13. Joshi GP, Landers DF. Audit in transfusion practice. J Eval Clin Pract 1998:4:141-6. Crossref 